\title{
Combined therapy trial with interferon alpha-2a and ablative therapy in the treatment of anogential
} warts

\author{
D K B Armstrong, R D Maw, W W Dinsmore, J Blaakaer, M A G Correa, L Falk, \\ A S Ferenczy, M Fortier, I Frazer, C Law, B M Moller, N Oyakawa
}

Department of Genitourinary Medicine, Royal Victoria Hospital Belfast, BT12 6BA D K B Armstrong R D Maw

W W Dinsmore

Gynaecology

Department,

University Hospital, Copenhagen, Denmark J Blaakaer

Hospital Naval

Marcilio Dias, Rio de

Janeiro, Brazil

M A G Correa

Hudkliniken,

Regionsjukhuset,

Orebro, Sweden

L Falk

The Sir Mortimer B

Davis Jewish General

Hospital, Montreal,

Canada

A S Ferenczy

Hopital du Saint-

Sacrement, Quebec,

Canada

M Fortier

Princess Alexandra

Hospital,

Woolloongabba,

Queensland, Australia

I Frazer

St George Hospital,

Kogarah, New South

Wales, Australia

C Law

Gynaecology

Department, Odense

Hospital, Odense,

Denmark

B M Moller

Hospital Das Clinicas,

San Paulo, Brazil

N Oyakawa

Correspondence to:

Dr D K B Armstrong.

Accepted for publication

14 November 1995
Objective: To determine whether the combination of systemically administered interferon alpha-2a and ablative surgery for the treatment of genital and/or perianal warts produces a $30 \%$ or greater improvement in lasting response rate compared with a control group receiving a combination of placebo and ablative therapy.

Design: Randomised, triple-blind, placebo-controlled trial using 1 or $3 \mathrm{MIU}$ of interferon alpha-2a or placebo administered subcutaneously three times weekly for 10 weeks in combination with ablative surgery.

Setting: International, multicentre study in 10 genitourinary medicine clinics.

Patients: Two hundred and fifty patients with anogenital warts.

Main outcome measures: Lasting response at week 38.

Results: Standard efficacy analysis at week 38 showed a lasting response in $51 \%(35 / 68)$ of 3 MIU interferon-treated patients, $48 \%(30 / 63)$ of 1 MIU interferon-treated patients and $43 \%$ $(29 / 67)$ of placebo-treated patients.

Conclusions: With the doses and regime described, treatment with interferon alpha-2a in combination with ablative therapy is not significantly superior in the treatment of anogenital warts than placebo and ablative therapy.

(Genitourin Med 1996;72:103-107)

Keywords: Human papillomavirus; interferon alpha-2a

\section{Introduction}

Anogenital warts are increasing in incidence and conventional management with chemical and physical ablative therapy is often associated with unsatisfactory response rates and a high incidence of recurrent disease..$^{1-3}$ Ablative therapy aims to remove clinically visible condylomata but latent human papillomavirus (HPV) infection in adjacent apparently normal epithelium may remain and be responsible for the high recurrence rates. ${ }^{4}$ Inclusion of a wider margin of apparently normal epithelium around lesions undergoing ablative treatment is recommended as one means of attempting to address this problem but in addition and perhaps more theoretically attractive is the use of a systemically administered agent which may act at all such sites of infection. The known antiviral, antiproliferative and immunomodulatory properties of interferons (IFNs) make such agents attractive adjuvant treatment to be used in conjunction with standard "debulking" ablative therapies. IFN treatment, however, is associated with characteristic adverse effects, involves significant expense and may necessitate more visits to the clinic to administer. It is important therefore that clear and significant clinical benefit be demonstrated if such agents are to be prescribed. This study was designed to test the hypothesis that the combination of subcutaneous IFN alpha-2a at a dose of $3 \mathrm{MIU}$ three times weekly for 10 weeks and physical ablative treatment would produce a $30 \%$ or more improvement in lasting response rates at week 38 in patients with external genital and/or perianal warts when compared with ablative therapy and placebo. The lasting response rate of a $1 \mathrm{MIU}$ dosage and the tolerability of such treatment were also to be evaluated.

\section{Patients and methods}

This study was conducted in 10 centres in six countries after study approval was obtained from each local medical ethics committee.

Patient selection Patients aged 18 years or older with clinically visible (without application of acetic acid) condylomata acuminata on the external genitalia and/or perianal area, likely to be cleared by ablative therapy within six weeks, who had not received treatment within one month of study entry were eligible. Patients were excluded if they had internal genital or anal canal lesions only, had had previous interferon treatment, were HIV antibody positive or had a history of immunomodulatory therapy within the last 12 months and/or therapy duration of more than three months. In addition, patients were excluded if they had evidence of malignant neoplastic disease (except intraepithelial neoplasia), a history of neurological disease, renal failure or autoimmune disease or an active sexually transmitted disease other than genital/perianal warts. Women who were pregnant, lactating or were not practicing an adequate form of contraception were also ineligible. Witnessed oral or written informed consent was obtained from all patients. 
Study design This was an international, multicentre, randomised, triple-blind, placebo-controlled combination therapy trial. Eligible patients were stratified according to sex and randomised to receive $3 \mathrm{MIU}$ or $1 \mathrm{MIU}$ of IFN alpha-2a (Roferon $^{(R)}$, AF Hoffmann-La Roche, Basel, Switzerland) or matched placebo injections subcutaneously three times per week for 10 consecutive weeks in combination with ablative therapy. Ablative therapy began at day 1 , with first injection, and continued, if required, until week 6 . Ablative therapy options included diathermy, electric cautery, diathermic loop or laser as viewed most appropriate by each investigator. The ablative therapy included $5 \mathrm{~mm}$ of the surrounding apparently normal epithelium. At the end of the 10 week treatment period, all patients with complete clearance of their lesions were followed up for 28 weeks after the end of treatment or until recurrence. Those with only a partial response at week 10 were withdrawn and treated as felt most appropriate by the investigator.

Assessment schedule A pre-study screen to include documentation of demographic details, duration of warts, and previous treatments and confirmation of eligibility for study entry was completed within two weeks of commencement of study treatment. Necessary haematological and biochemical measures were checked and HIV antibody testing and pregnancy tests performed. A representative biopsy specimen was taken for histology and HPV DNA typing. Analysis was performed at a central laboratory and was blind to treatment assignment. Detection of HPV DNA in biopsy tissue was performed by in-situ DNA hybridisation (HPV 6, 11, 16, 18, 31, 33). All negative samples were further analysed by polymerase chain reaction techniques.

A baseline assessment was performed immediately prior to the first injection and ablative treatment on day 1 to include a description of location, type and number of lesions and estimated operability.

An assessment of disease state was carried out at the end of weeks 4, 6 and 10. Any adverse events, intercurrent illnesses or changes in concomitant medication were noted. The number and type of ablative treatments was recorded at the end of week 6 . Patients with a partial response only at week 10 assessment were withdrawn. Patients with a complete response at week 10 were seen every four weeks during the 28 weeks of follow-up or until there was recurrence. Patients noting a recurrence between week 10 and week 38 were asked to return to the trial centre immediately where the next monthly assessment was performed. They were subsequently withdrawn and treatment was at the discretion of the supervising physician.

Laboratory investigations Blood was taken for haemoglobin concentration, white blood cell count, platelet count, creatinine and AST during the pre-study screen, at weeks $0,4,10$ and 14. In the event of unexplained or unexpected test value abnormalities, the tests were repeated immediately and followed up until the results returned to the normal range and/or an adequate explanation of the abnormality was found.

Criteria for exclusion from efficacy analysis Patients were excluded from standard analysis of efficacy if they violated entry criteria, became pregnant, missed three consecutive injections or did not receive a minimum of 26 injections, or in the case of recurrence before week 10 a minimum number defined by the week of recurrence. The use of systemic or topical treatment likely to interfere with evaluation of efficacy or loss to follow-up also constituted grounds for withdrawal from standard analysis of efficacy.

An intent-to-treat analysis included all patients who received study medication and had at least one post-baseline assessment. All such patients were included in the analysis of safety.

Statistical analysis Sample size was calculated to detect a $30 \%$ difference in response rates between placebo and IFN alpha-2a (3 MIU)treated patients with $80 \%$ power using a twosided test at the 5\% level of significance. Analysis was undertaken without knowledge of the treatment code. The hypothesis had assumed a lasting response would be achieved in approximately $70 \%$ of patients treated with 3 MIU Interferon alpha-2a and $40 \%$ of those treated with placebo. This assumption proved invalid and therefore only descriptive statistics were used. The frequency of responders, the response rate and the $95 \%$ confidence interval defined by the Pearson-Clopper limits were calculated for the standard analysis population and the intent-to-treat population.

\section{Results}

In total, 250 patients were recruited in 10 centres. Two hundred and forty-nine received at least one injection. Of these, 81 were randomised to placebo, 83 to IFN alpha-2a ( 3 $\mathrm{MIU}$ ) and 85 to IFN alpha-2a (1 MIU).

Demographic data and pre-study characteristics There were no significant differences between treatment groups in age, weight, height, sex distribution, race, sexual orientation or smoking habit. The groups were comparable for previous treatments for their anogenital warts and for concomitant diseases and medication. Table 1 summarises pretreatment lesion characteristics which showed no notable differences between treatment groups. The majority of internal warts involved the vagina in all treatment groups with smaller numbers affecting the cervix, anal canal, urethral meatus and urethra.

\section{Histopathology and HPV typing data}

Tables 2 and 3 outline the microscopic morphology and HPV DNA types detected respectively in biopsy specimens taken. The predominant microscopic morphology was 
Table 1 Pre-treatment characteristics

\begin{tabular}{|c|c|c|c|c|}
\hline Parameter & & $\begin{array}{l}\text { Placebo } \\
N=81\end{array}$ & $\begin{array}{l}I F N(1 M I U) \\
N=85\end{array}$ & $\begin{array}{l}I F N(3 M I U) \\
N=83\end{array}$ \\
\hline $\begin{array}{l}\text { Duration of disease } \\
\text { (months) }\end{array}$ & $\begin{array}{l}\text { median } \\
\text { range }\end{array}$ & $\begin{array}{l}7 \\
1-120\end{array}$ & $\begin{array}{l}9 \\
1-168\end{array}$ & $\begin{array}{l}6 \\
1-120\end{array}$ \\
\hline Operability - No (\%) & $\begin{array}{l}\text { operable } \\
\text { difficult } \\
\text { at limit }\end{array}$ & $\begin{array}{c}71(88) \\
7(9) \\
3(4)\end{array}$ & $\begin{array}{c}79(93) \\
5(6) \\
1(1)\end{array}$ & $\begin{array}{c}80(96) \\
1(1) \\
2(2)\end{array}$ \\
\hline $\begin{array}{l}\text { Number of external } \\
\text { lesions-No }(\%)\end{array}$ & $\begin{array}{l}1-5 \\
6-10 \\
11-15 \\
16-20 \\
>20 \\
\text { not countable }\end{array}$ & $\begin{array}{c}14(17) \\
20(25) \\
9(11) \\
6(7) \\
6(7) \\
26(32)\end{array}$ & $\begin{array}{c}17(20) \\
16(19) \\
15(18) \\
4(5) \\
11(13) \\
21(25)\end{array}$ & $\begin{array}{c}21(26) \\
22(27) \\
7(9) \\
7(9) \\
6(7) \\
19(23)\end{array}$ \\
\hline $\begin{array}{l}\text { Location of external } \\
\text { lesions-No }(\%)\end{array}$ & $\begin{array}{l}\text { genital } \\
\text { perianal } \\
\text { both }\end{array}$ & $\begin{array}{c}52(64) \\
7(9) \\
22(27)\end{array}$ & $\begin{array}{c}54(64) \\
7(8) \\
23(27)\end{array}$ & $\begin{array}{c}50(61) \\
7(9) \\
25(30)\end{array}$ \\
\hline $\begin{array}{l}\text { Presence of internal } \\
\text { lesions-No }(\%)\end{array}$ & $\begin{array}{l}\text { yes } \\
\text { no }\end{array}$ & $\begin{array}{l}27(33) \\
54(67)\end{array}$ & $\begin{array}{l}19(22) \\
66(78)\end{array}$ & $\begin{array}{l}23(28) \\
60(72)\end{array}$ \\
\hline
\end{tabular}

Table 2 Microscopic morphology of biopsies

\begin{tabular}{lllll}
\hline Classification & $\begin{array}{l}\text { Placebo } \\
n(\%)\end{array}$ & $\begin{array}{l}\text { IFN (1 MIU) } \\
n(\%)\end{array}$ & $\begin{array}{l}\text { IFN }(3 \mathrm{MIU}) \\
n(\%)\end{array}$ & $\begin{array}{l}\text { Total } \\
n(\%)\end{array}$ \\
\hline Papillary & $50(62 \cdot 5)$ & $56(66 \cdot 7)$ & $52(62 \cdot 7)$ & $158(64 \cdot 0)$ \\
Flat & $11(13 \cdot 8)$ & $12(14 \cdot 3)$ & $10(12 \cdot 0)$ & $33(13 \cdot 4)$ \\
Pigmented papulosis & $18(22 \cdot 5)$ & $15(17 \cdot 9)$ & $20(24 \cdot 1)$ & $53(21 \cdot 5)$ \\
Bowenoid papulosis & $1(1 \cdot 2)$ & 0 & $1(1 \cdot 2)$ & $2(0 \cdot 8)$ \\
Pigmented naevus & 0 & $1(1 \cdot 2)$ & 0 & $1(0 \cdot 4)$ \\
Total & 84 & 83 & 80 & 247 \\
\hline
\end{tabular}

Table 3 HPV DNA typing of biopsies

\begin{tabular}{lllll}
\hline Type & $\begin{array}{l}\text { Placebo } \\
n(\%)\end{array}$ & $\begin{array}{l}\text { IFN }(1 \mathrm{MIU}) \\
n(\%)\end{array}$ & $\begin{array}{l}\text { IFN }(3 \mathrm{MIU}) \\
n(\%)\end{array}$ & $\begin{array}{l}\text { Total } \\
n(\%)\end{array}$ \\
\hline 6 & $29(36 \cdot 7)$ & $36(42 \cdot 9)$ & $34(41 \cdot 0)$ & $99(40 \cdot 2)$ \\
11 & $22(27 \cdot 9)$ & $22(26 \cdot 2)$ & $18(21 \cdot 7)$ & $62(25 \cdot 2)$ \\
18 & $1(1 \cdot 3)$ & 0 & $4(4 \cdot 8)$ & $5(2 \cdot 0)$ \\
31 & $1(1 \cdot 3)$ & $2(2 \cdot 4)$ & $2(2 \cdot 4)$ & $5(2 \cdot 0)$ \\
Other & $3(3 \cdot 8)$ & $2(2 \cdot 4)$ & $6(7 \cdot 2)$ & $11(4 \cdot 5)$ \\
Negative & $23(29 \cdot 1)$ & $22(26 \cdot 2)$ & $19(22 \cdot 9)$ & $64(26 \cdot 0)$ \\
Total & 79 & 84 & 83 & 246 \\
\hline
\end{tabular}

Table 4 Overall assessment of response to treatment

\begin{tabular}{llll}
\hline All centres & $\begin{array}{l}\text { Placebo } \\
n(\%)(95 \%-C I)\end{array}$ & $\begin{array}{l}\text { IFN }(1 \mathrm{MIU}) \\
n(\%)(95 \%-C I)\end{array}$ & $\begin{array}{l}\text { IFN }(3 \mathrm{MIU}) \\
n(\%)(95 \%-C I)\end{array}$ \\
\hline $\mathrm{N}$ & 67 & 63 & 68 \\
Lasting response & $29(43)(31-56)$ & $30(48)(35-61)$ & $35(51)(39-64)$ \\
Treatment failures & $38(57)$ & $33(52)$ & $33(49)$ \\
\hline
\end{tabular}

papillary. The individual whose biopsy specimen showed a pigmented naevus was excluded from efficacy analysis. There was a low frequency of dysplasia with four cases of mild dysplasia in the 3 MIU IFN group, three in the 1 MIU IFN group and one in the placebo-treated group. Only two cases of moderate dysplasia were detected with one case in the $3 \mathrm{MIU}$ IFN group and one case in the placebo-treated group. No cases of severe dysplasia were detected. HPV types 6 and 11 were most commonly detected. The three treatment groups were comparable.

\section{Efficacy analysis}

The primary efficacy analysis was to determine the number of patients who had a lasting response at week 38 , i.e. complete clearance of all clinically visible lesions and no recurrence thereafter up to and including week 38 .
Treatment failures included both patients who showed only partial clearance of lesions by week 10 or recurrence prior to or at week 38 . Table 4 summarises the standard analysis of efficacy of the three treatment groups. At week 38,35 of the 68 evaluable patients in the 3 MIU IFN group (51\%), 30 of the 63 patients in the 1 MIU group (48\%) and 29 of the 67 placebo patients $(43 \%)$ had lasting responses. The 33 treatment failures $(49 \%)$ in the 3 MIU IFN group included 10 with a partial response at week 10 and 23 patients with recurrences. Thirty-three patients $(52 \%)$ in the 1 MIU were treatment failures with nine showing partial response at week 10 and 24 patients noting recurrence. In the placebo group the 38 patients $(57 \%)$ classified as treatment failures comprised 14 with a partial response at week 10 and 24 with recurrences at or before week 38.

The results of an intent-to-treat analysis including all patients who had received treatment did not differ substantially from the results of the above standard efficacy analysis. As a result of small numbers of patients at each centre it was not possible to draw clear conclusions as to any effect of the centre on overall response rates.

Clearly the combination of $3 \mathrm{MIU}$ of IFN alpha-2a and ablative therapy did not produce an improvement of $30 \%$ in lasting response rate in excess of that produced by placebo and ablative therapy. Hence the test hypothesis is invalid.

\section{Ablative therapy}

The proportions of patients treated with each type of ablative therapy and the number of ablative treatments given were similar in all three treatment groups. The majority of patients received one or two treatments for external lesions and a single treatment for internal lesions.

\section{Safety analysis}

One hundred and eighteen $(47 \%)$ of the 249 patients who received IFN or placebo experienced adverse effects. Forty-three of these were in the 1 MIU IFN group, 42 in the 3 MIU group and 33 in the placebo group.

The most frequently reported adverse events in the IFN-treated patients were headaches, fatigue, flu-like symptoms, local erythema, dizziness and myalgia. The most common adverse events in placebo-treated patients were headache, fatigue, dizziness, nasal congestion and flu-like symptoms. The majority of adverse events were of mild severity and most were considered by the investigator to be probably or possibly related to the study drug.

\section{Laboratory data}

All HIV antibody tests were negative. There were no clinically relevant changes in median haemoglobin, creatinine or AST levels during the study. Median leucocyte count fell in both 3 MIU and 1 MIU IFN groups at week 4 (by $1.2 \times 10^{3} / 1$ and $1.4 \times 10^{3} / 1$ respectively) but in each case counts returned close to pretreat- 
ment levels by week 14. Median platelet levels declined slightly in both IFN-treated groups at week 4 . In the $1 \mathrm{MIU}$ IFN group the platelet count remained at this lower level at week 14 $\left(270.5 \times 10^{3} / \mathrm{L}\right.$ compared with a pretreatment level of $283 \times 10^{3} / 1$ ) but in the $3 \mathrm{MIU}$ group returned to near pretreatment levels.

\section{Discussion}

HPV infection of the anogenital epithelium is a multicentric process and in addition to the production of clinically visible condylomata acuminata may produce latent and clinically inapparent "disease". It is this phenomenon which may explain the often inadequate response rates and unacceptably high recurrence rates with currently available conventional chemical and physical ablative therapies. ${ }^{1-3}$ Interferons are known to possess antiviral, anti-proliferative and immunomodulatory effects and as such were thought to represent attractive agents in the treatment of HPV infection. Early trials with IFN monotherapy showed somewhat conflicting results and comparison between studies is difficult because of variations in study design, IFN subtype, route of administration, nature of warts treated and endpoint measures of efficacy chosen. Some degree of clinical efficacy has been demonstrated by studies using parenteral and intra-lesional routes of administration in both primary and recalcitrant warts ${ }^{5-11}$ but several of these studies involved relatively small numbers of patients, were open and uncontrolled. One large randomised open study, however, compared systemically administered IFN alpha-2a with podophyllin in the treatment of primary anogenital warts and found IFN to be a significantly less effective form of monotherapy..$^{12}$ Indeed it is the general consensus that IFN monotherapy is not superior to currently available standard therapeutic techniques. ${ }^{11}$

The potential therapeutic benefit of a combination of a standard chemical or physical ablative treatment and IFN therapy has subsequently been addressed. Douglas et al demonstrated an improvement in complete response rate in patients treated with a combination of intralesional IFN alpha-2b and podophyllin versus podophyllin alone. ${ }^{13}$ Several other authors have also shown a beneficial adjuvant effect of systemic IFN therapy when used in combination with ablative therapy for recalcitrant anogenital warts. ${ }^{14-16}$ It is notable, however, that several of these reports have methodological limitations in terms of patient numbers, limited controls and duration of follow-up. Recently three large well conducted randomised, placebo-controlled combination therapy trials have failed to demonstrate a significant improvement in either complete response or recurrence rates when systemic interferon alpha-2a was combined with laser surgery, ${ }^{17}$ cryotherapy ${ }^{18}$ or podophyllin. ${ }^{19}$ This present study was evaluating the effect of adjuvant systemic IFN alpha-2a in combination with ablative surgery on the rate of lasting response, that is persistence of complete clear- ance, up to and including 28 weeks after cessation of IFN therapy. Interferon therapy is associated with well described side effects and involves additional expenditure. It follows that clear clinical benefit should be demonstrated before such treatment could be justified. It was considered that in order for such adjuvant treatment to be regarded as therapeutically useful a lasting response rate of at least $30 \%$ over and above the placebo response was necessary. The number of patients recruited was sufficient to supply the required statistical power to test our initial hypothesis. The treatment groups were comparable for prestudy lesion characteristics and the histopathology and HPV DNA findings are similar to other large series with a predominance of papillary microscopic morphology, types 6 and $11 \mathrm{HPV}$ DNA and infrequent evidence of dysplasia. ${ }^{12} 17$ As such our study population would appear to be representative. With a lasting response rate of $51 \%$ in the $3 \mathrm{MIU}$ IFN group compared with $43 \%$ in the placebo treated group clearly our test hypothesis was invalid. An intermediate value of $48 \%$ was obtained with the $1 \mathrm{MIU}$ IFN dose. Complete response rates at week 10 were also comparable between treatment groups. The most frequently reported adverse events were flu-like symptoms and were generally mild.

In summary we conclude that although well tolerated, interferon alpha-2a, given at $1 \mathrm{MIU}$ or 3 MIU three times per week in combination with ablative surgery was not found to be superior in the treatment of anogenital warts when compared with treatment with ablative therapy plus placebo.

1 Gabriel G, Thin RNT. Treatment of anogenital wartscomparison of trichloracetic acid and podophyllin versus comparison of trichloracetic acid and podophylin 6 .

2 Stone KM, Becker TM, Hadgu A, Kraus SJ. Treatment of external genital warts: a randomised clinical trial comparing podophyllin, cryotherapy and electrodessication. Genitourin Med 1990;66:16-19.

3 Ling MR. Therapy of genital human papillomavirus infections, part II: Methods of treatment. Int $\mathcal{f}$ Dermato 1992;31:769-76.

4 Ferenczy A, Mitao M, Nagai N, et al. Latent papillovirus and recurring genital warts. $N$ Engl $f$ Med 1985;313 784-8.

5 Welander CE, Homesley HD, Smiles KA, Peets EA. Intralesional interferon alfa-2b for the treatment of genital warts. Am ₹ Obstet Gynecol 1990;162:348-54.

6 Reichman RC, Oakes D, Bonnez W, et al. Treatment of condyloma acuminatum with three different interferons condyloma acuminatum with three different interferons administer

7 Gall SA, Hughes CE, Mounts P, et al. Efficacy of human lymphoblastoid interferon in the therapy of resistan condyloma acuminata. Obstet Gynecol 1986;67:643-51.

8 Eron LJ, Judson F, Tucker S, et al. Interferon therapy for condyloma acuminata. $N$ Eng $f$ Med 1986;315:1059-64.

9 Friedman-Kien AE, Eron LJ, Canant M, et al. Natura interferon alfa for treatment of condylomata acuminata. ЭAMA 1988;259:533-8.

10 Kirby PK, Kiviat N, Beckman A, et al. Tolerance and efficacy of recombinant human interferon gamma in the 85:183-8.

11 Reichman RC, Oakes D, Bonnez W, et al. Treatment of condyloma acuminata with three different interferoncondyloma acuminata with three different interferonalpha preparations administered parenterally: A doubleblind, placebo-controlled trial. $f$ Infect Dis 1990;162: 1270-6.

12 Anon. A comparison of interferon alfa-2a and podophyllin in the treatment of primary condylomata acuminata Genitourin Med 1991;67:394-9.

13 Douglas JM, Eron LJ, Judson FN, et al. A randomised tria of combination therapy with intralesional interferon alpha-2b and podophyllin versus podophyllin alone for therapy of anogenital warts. F Infect Dis 1990;162:52-9. 
14 Petersen CS, Bjerring P, Larsen J, et al. Systemic interferon alpha-2b increases the cure rate in laser treated patients with multiple persistent genital warts: a placebocontrolled study. Genitourin Med 1991;67:99-102.

15 Hopfl RM, Sandbichler M, Zelger BWH, Conrad FG Fritsch PO. Adjuvant treatment of recalcitrant genitoanal warts with systemic recombinant interferon-alpha-2c. Acta Derm Venereol 1992;72:383-6.

16 Reid R, Greenberg MD, Pizzuti DJ, et al. Superficial laser vid R, Greenberg MD, Pizzut DJ, et al. Superficial laser vulvectomy - enhanced by adjuvant systemic interferon.

7 Anon. Randomised placebo-controlled double-blind combined therapy with laser surgery and systemic interferon alpha-2a in the treatment of anogenital condylomata acuminata. $\mathcal{F}$ Infect Dis 1993;167: 824-9.

18 Handley JM, Horner T, Maw RD, Lawther H, Dinsmore WW. Subcutaneous interferon alpha $2 \mathrm{a}$ combined with cryotherapy vs cryotherapy alone in the treatment of primary anogenital warts: a randomised observer blind placebo-controlled study. Genitourin Med 1991;67: placebo-c.

19 Armstrong DKB, Maw RD, Dinsmore WW, et al. Randomised, double blind, parallel group study to compare subcutaneous interferon alfa-2a plus podophyllin with placebo plus podophyllin in the treatment of primary condylomata acuminata. Genitourin Med 1994;70: 389-93. 